\title{
Basic psychological needs and neurophysiological responsiveness to decisional conflict: an event-related potential study of integrative self processes
}

\author{
Stefano I. Di Domenico ${ }^{1,2} \cdot$ Ada $^{3} e^{3} \cdot$ Yichuan Liu $^{4} \cdot$ Hasan Ayaz $^{4,5,6} \cdot$ Marc A. Fournier $^{2}$
}

Published online: 23 May 2016

(C) Psychonomic Society, Inc. 2016

\begin{abstract}
Fulfillment of the basic psychological needs for competence, relatedness, and autonomy is believed to facilitate people's integrative tendencies to process psychological conflicts and develop a coherent sense of self. The present study therefore used event-related potentials (ERPs) to examine the relation between need fulfillment and the amplitude of conflict negativity $(\mathrm{CN})$, a neurophysiological measure of conflict during personal decision making. Participants completed a decision-making task in which they made a series of forced choices according to their personal preferences. Three types of decision-making situations were created on the basis of participants' unique preference ratings, which were obtained prior to ERP recording: low-conflict situations (choosing between an attractive and an unattractive option), highconflict approach-approach situations (choosing between two similarly attractive options), and high-conflict avoidance-avoidance situations (choosing between two similarly unattractive options). As expected, $\mathrm{CN}$ amplitudes were larger in high- relative to low-conflict situations, and source
\end{abstract}

Stefano I. Di Domenico

stefanoddmn@gmail.com; Stefano.didomenico@acu.edu.au

1 Institute for Positive Psychology and Education, Australian Catholic University, 25A Barker Road, Strathfield, NSW 2135, Australia

2 Department of Psychology, University of Toronto Scarborough, Toronto, ON, Canada

3 Center for Vision Research, York University, Toronto, ON, Canada

4 School of Biomedical Engineering, Science and Health Systems, Drexel University, Philadelphia, PA, USA

5 Department of Family and Community Health, University of Pennsylvania, Philadelphia, PA, USA

6 Division of General Pediatrics, Children's Hospital of Philadelphia, Philadelphia, PA, USA localization analyses suggested that the anterior cingulate cortex was the generating structure of the CN. Most importantly, people reporting higher need fulfillment exhibited larger $\mathrm{CN}$ amplitudes in avoidance-avoidance situations relative to lowconflict situations; to a lesser extent, they also exhibited larger $\mathrm{CN}$ amplitudes in approach-approach situations relative to low-conflict situations. By contrast, people reporting lower need fulfillment exhibited $\mathrm{CN}$ amplitudes that poorly discriminated the three decision situations. These results suggest that need fulfillment may promote self-coherent functioning by increasing people's receptivity to and processing of events that challenge their abilities to make efficient, self-congruent choices.

Keywords Basic psychological needs · Conflict negativity · Conflict monitoring · Decision making · Psychological conflict $\cdot$ Self-determination theory

Imagine a young person deciding between two career paths. Like other self-defining decisions, choosing and committing to one career path and foreclosing others entails a careful weighing of one's interests and priorities, a process that can be fraught with conflict, uncertainty, and anxiety (Hirsh, Mar, \& Peterson, 2012; Schwartz, 2000). Despite the discomfort that major life decisions sometimes entail, conflicts can also offer people a perspective from which to clarify their core values, focus their life goals, and thereby make choices that are more congruent with their sense of self (Carver \& Scheier, 1998; McAdams, 2013; W. R. Miller \& Rollnick, 2002; Weinstein, Przybylski, \& Ryan, 2013). Decisional conflicts, then, hold the potential to provide "grist for the mill" of selfcoherence and development, but what conditions facilitate people's engagement with and processing of conflict-laden experiences in the first place? 
Research within self-determination theory (SDT; Deci \& Ryan, 2000) has shown that people's abilities to develop and act from an integrated sense of self are facilitated by developmental and situational conditions that fulfill basic psychological needs for competence, relatedness, and autonomy (Chirkov, Ryan, \& Sheldon, 2011; Sheldon, 2014; Vansteenkiste \& Ryan, 2013). That is, people's capacities to be motivated and to regulate behavior in a coherent and authentic way depend on the extent to which they can exercise their skills and master challenging activities (fulfilling competence), connect with others and develop satisfying relationships (fulfilling relatedness), and self-organize and volitionally enact their behaviors (fulfilling autonomy). By contrast, people are more likely to act in less authentic and in more defensive or fragmented ways in contexts that thwart and frustrate these basic psychological needs (Vansteenkiste \& Ryan, 2013). Although much work has examined the experiential and behavioral outcomes of need fulfillment, research has only begun to investigate the neurophysiological basis of need fulfillment in the facilitation of integrative processes.

The purpose of the present study is to examine the integrative function of need fulfillment at the neurophysiological level of analysis. We propose that need fulfillment amplifies people's neurophysiological responsiveness to decisional conflicts that call for the revision of old self-knowledge representations or the development of new self-knowledge representations in the service of more efficient, self-congruent choices. We hypothesize that this enhanced neurophysiological responsiveness to decision-making conflicts is evidenced by the amplitude of conflict negativity $(\mathrm{CN})$, a negative deflection on electroencephalography (EEG) that occurs immediately after behavioral selections in forced-choice scenarios (Nakao, Bai, Nashiwa, \& Northoff, 2013; Nakao, Mitsumoto, et al., 2010; Nakao, Takezawa, Shiraishi, \& Miyatani, 2009).

\section{Decision-making conflict: a useful phenomenon for examining the role of basic psychological needs in the facilitation of integrative processes}

Psychological conflict has long been a focus in the study of personality development because it can illuminate the processes through which people construct and enact a coherent sense of self (Freud, 1940/1969; Jung, 1951/1978). Indeed, many classic theories of personality share the idea that people have natural growth tendencies to overcome inner conflicts and to establish a coherent sense of self that, in turn, provides the basis for healthy and effective functioning. For example, Rogers (1961) posited that personality integration entails "an increasingly clear facing of contradictions and incongruences in experience" (p. 142). Rogers thus conceptualized personality coherence not as a fixed self-concept that is invulnerable to conflicts, but as an ongoing process of engaging with uncertainties and, through that work, differentiating and integrating one's core sense of self. Piaget converged on a similar set of ideas. He proposed that psychological conflicts arise when people cannot easily reconcile novel experiences with their existing ways of making sense of themselves or the world. According to Piaget, conflicts can foster growth by spurring the construction of new cognitive-behavioral schemes that, when integrated with existing regulatory structures, expand one's mastery over both inner and outer environments (Evans, 1973).

Drawing on these classic perspectives, SDT (Deci \& Ryan, $1985,2000)$ proposes that people are inherently motivated to resolve psychological conflicts and to continually elaborate and refine their sense of self. Within SDT, integrative processes refer to people's constructive tendencies to respond to psychological conflicts and develop and act from a coherent sense of self (Deci \& Ryan, 1991; Ryan, 1995). When functioning in an integrated manner, people are less defensive and more interested in making sense of incongruous and potentially threatening events and are more aware of their emotions, motives, and value conflicts (Weinstein et al., 2013). SDT further stipulates that integrative processes function most effectively under developmental and situational circumstances that support the fulfillment of basic psychological needs, specifically, the needs for competence (feeling effectual), relatedness (feeling connected with others), and autonomy (feeling volitional). Psychological needs thus specify the experiential conditions that energize integrative processes and help account for both intra- and interindividual differences in selfcoherent functioning (see Table 1). This idea is supported by both basic and applied research in life domains such as psychotherapy, work, and education (Deci \& Ryan, 2008). Operating from the assumption that integrative processes underlie healthy development, SDT practitioners focus on creating the social conditions that help people to fulfill their needs and function in a self-coherent manner (Ryan \& Deci, 2008).

Most recently, researchers have begun to investigate the neurophysiological substrates of integrative processes. Selfcoherent functioning entails that behavior be guided by one's abiding interests, goals, and values (Weinstein et al., 2013). Decision-making tasks that do not presume objectively "correct" or "incorrect" choices and instead challenge respondents to resolve decisional conflicts on the basis of selfrelevant criteria (i.e., their personal preferences) can therefore provide a means to examine integrative processes in controlled laboratory settings. In this vein, Di Domenico et al. (2013) used functional near-infrared spectroscopy (fNIRS) to examine the relationship between need fulfillment and the activity of the medial prefrontal cortex (MPFC), a region that plays an important role in the recruitment of the selfknowledge representations used to resolve decisional conflicts (Nakao, Osumi, et al., 2009; Nakao, Osumi, et al., 2010). 
Table 1 Aspects of self-coherent functioning that are conceptualized and researched within SDT as expressions of personality integration

\begin{tabular}{lcc}
\hline Research topic & $\begin{array}{c}\text { Brief description of the phenomenon as } \\
\text { an expression of integrative processes }\end{array}$ & Important references \\
\hline Intrinsic motivation & $\begin{array}{c}\text { One's activities are spontaneously enacted } \\
\text { out of personal interest. } \\
\text { One's sociocultural practices and goal-directed } \\
\text { Internalization }\end{array}$ & $\begin{array}{c}\text { Dectivities are brought into line with one's } \\
\text { Ryan (1999) }\end{array}$ \\
Intrinsic goal strivings & abiding interests and values. & Ryan and Connell (1989) \\
One's goal pursuits afford direct satisfaction & of basic psychological needs. & Kasser and Ryan \\
Mindfulness & One's behavior is informed by a reflective awareness & (1993, 1996) \\
Identity integration & of one's emotions and impulses. & Brown, Ryan, and \\
& One's identity is nondefensively explored; one's & Creswell (2007) \\
past self is seen as being connected and & Weinstein, Deci, and \\
relevant to the current self. & Ryan (2011)
\end{tabular}

Within SDT, phenomena that reflect self-coherent functioning are conceptualized in terms of an overarching tendency toward psychological growth and integration, the ongoing expressions of which are facilitated by the fulfillment of competence, relatedness, and autonomy. Adapted from "In Search of Integrative Processes: Basic Psychological Need Satisfaction Predicts Medial Prefrontal Activation During Decisional Conflict," by S. I. Di Domenico, M. A. Fournier, H. Ayaz, and A. C. Ruocco, 2013, Journal of Experimental Psychology: General, 142, 967-978. Adapted with permission

Several days before neuroimaging, participants completed a survey that asked them to rate the extent to which they believed that they might experience personal satisfaction and enjoyment in a number of occupations (e.g., musician, dentist, comedian) as a possible future career. These ratings were then used to create idiographically tailored "occupational choice" tasks that featured low- and high-conflict conditions. In these conditions, two occupational words were presented side by side, and participants were asked to select the occupation that they would prefer as a future career (e.g., Which occupation would you prefer, musician or dentist?). While the word pairs in the low-conflict condition consisted of occupations with greater rating differences between them (i.e., an attractive and unattractive occupation), those in the high-conflict condition consisted of occupations that were similarly rated (i.e., two attractive or unattractive occupations).

The study by Di Domenico et al. (2013) found that higher need fulfillment predicted longer reaction times and elevated levels of MPFC activity during high- relative to low-conflict situations. These results are in keeping with the idea that need fulfillment promotes self-coherent functioning as they suggest that people with higher need fulfillment self-reflect when attempting to resolve decisional conflicts. A key limitation of this functional imaging study, however, was its use of a blocked design and the limited temporal resolution of fNIRS. Specifically, what remains unclear is whether need fulfillment is associated with amplified responsiveness to the conflict produced in the moment of choosing one item and foregoing a similarly valued alternative. Examining conflict processing at this later point in the decision-making stream is necessary for testing if need fulfillment is associated with people's responsiveness to events that signal a demand for enhanced self-knowledge representations to guide decision making. The event-related potential (ERP) technique (Luck, 2005) is useful for examining this aspect of conflict-ridden decisions because this method has very high temporal resolution and can therefore be used to examine conflict processing in the milliseconds following choice behavior.

Indeed, in previous studies using occupational choice paradigms, Nakao and colleagues measured the degree of conflict in the moments of choice selection with the amplitude of the conflict negativity $(\mathrm{CN})$, a pronounced negative deflection on EEG that appears within $60 \mathrm{~ms}$ of making a behavioral selection (Nakao, Bai, Nashiwa, \& Northoff, 2013; Nakao, Mitsumoto, et al., 2010; Nakao, Takezawa, Shiraishi, \& Miyatani, 2009). The $\mathrm{CN}$ is believed to be generated by a conflict-monitoring system in the anterior cingulate cortex (ACC), a "cortical alarm bell" that signals the need for stronger top-down inputs to more efficiently guide decision making (Nakao, Ohira, \& Northoff, 2012; Nakao, Osumi et al., 2010; also see Hirsh et al., 2012). Larger $\mathrm{CN}$ amplitudes are thus believed to reflect the neural competition between available choice selections and the need for enhanced self-knowledge representations in the service of efficient decision making (cf. Botvinick, 2007; Botvinick et al., 2001; Shenhav, Botvinick, \& Cohen, 2013). Support for this conflict-monitoring interpretation of the $\mathrm{CN}$ comes from experimental studies showing that strengthening self-knowledge inputs (i.e., increasing top-down control) prior to decision making mitigates response conflict. Specifically, Nakao and colleagues found that $\mathrm{CN}$ amplitudes were smaller when participants were asked to reflect upon biasing self-knowledge representations immediately before decision-making trials on the occupational choice task (Nakao, Takezawa, et al., 2009; Nakao, Mitsumoto, et al., 2010).

This research on the $\mathrm{CN}$ as a neural signal of response conflict and the need for enhanced executive control provides 
an empirical avenue to further specify and investigate the neurophysiological substrates of integrative processes. According to SDT, self-development is an active and ongoing process in which people strive to make self-congruent decisions by relating situational affordances to their abiding goals and values. From this developmental perspective, events that challenge people's capacities to make self-endorsed choices are opportunities for them to refine their existing self-knowledge representations. This integrative growth process thus entails that one be receptive to decisional conflicts, which indicate that one's current self-knowledge representations require adaptive revision and elaboration in order to provide the basis for efficient, self-congruent decision making (Deci \& Ryan, 1985; Ryan, Kuhl, \& Deci, 1997; Weinstein et al., 2013). We accordingly propose that the $\mathrm{CN}$ can be used to assess the operation of integrative processes as posited by SDT. Specifically, if need fulfillment increases people's readiness to adjust existing regulatory structures or to construct new ones in the service of self-coherence when the necessity strikes, then people who report higher need fulfillment ought to evidence larger $\mathrm{CN}$ amplitudes when they cannot easily resolve conflicts within their personal preferences.

Decades of work on conflict-ridden decision making, starting with the seminal ideas of Lewin (1935) and the research of N. E. Miller (1944, 1959), provides a useful starting point for operationalizing the conditions in which need fulfillment ought to predict larger $\mathrm{CN}$ amplitudes. These researchers contrasted low-conflict situations (i.e., choosing between attractive and unattractive alternatives) with two basic types of high-conflict situations. In approach-approach conflicts, an individual must choose between two similarly attractive alternatives. In avoidance-avoidance conflicts, an individual must choose between two similarly unattractive alternatives. Miller's earliest studies showed that avoidance-avoidance conflicts are more difficult to resolve than approachapproach conflicts because as individuals reluctantly approach either unattractive option, they become increasingly motivated to retreat away from it. Whereas indecision and choice vacillation during avoidance-avoidance scenarios can theoretically go on indefinitely (unless the situation necessitates a response), approach-approach conflicts are more easily resolved because even slight inclinations toward one option will result in an increasing tendency to select that option and thereby reduce the conflict.

Indeed, people produce longer reaction times when choosing between unattractive options relative to attractive options and experience such decisions to be more difficult (e.g., Arkoff, 1957; Diederich, 2003; Kamano, 1963; Minor, Miller, \& Ditrichs, 1968; Murray, 1975). People are also more likely to defer making choices involving avoidance-avoidance conflicts (Anderson, 2003; Dhar \& Nowlis, 1999), and such decisions provoke more psychological discomfort than do their decisions in approach-approach scenarios (Shultz,
Léveillé, \& Lepper, 1999). An fMRI study by Blair et al. (2006) found higher levels of ACC activity and longer reaction times when participants decided which was the lesser of two punishments than when they decided which was the greater of two rewards. Together, these findings indicate that avoidance-avoidance conflicts are more difficult to resolve than approach-approach conflicts and therefore suggest that progressively larger $\mathrm{CN}$ amplitudes should be observed across low-conflict, approach-approach, and avoidance-avoidance conflict situations. ${ }^{1}$

These expected differences in $\mathrm{CN}$ amplitude across the three basic conflict situations may be increased by self-reflection, which enables one to more sharply compare their current behavior against their internalized standards and values (Brown et al., 2007; Carver \& Scheier, 1998; Duval \& Wicklund, 1972). Given that need fulfillment predicts increased MPFC activity and presumably increased selfreflection during the regulation of decisional conflicts (Di Domenico et al., 2013), we hypothesized that need fulfillment would potentiate the amplitude of the $\mathrm{CN}$ across decisionmaking situations in which existing self-knowledge structures could not be used to efficiently guide decision making within people's personal preferences. Specifically, we hypothesized that higher need fulfillment would predict larger $\mathrm{CN}$ amplitudes in high- relative to low-conflict situations and in avoidance-avoidance situations relative to approachapproach situations. Such a result would be consistent with the idea that need fulfillment increases people's receptivity to and processing of events that challenge their abilities to make efficient, self-congruent choices (Deci \& Ryan, 1985; Ryan et al., 1997; Weinstein et al., 2013). In the present study, we tested these hypotheses using an elaborated version the occupational choice paradigm (Di Domenico et al., 2013; Nakao et al., 2013; Nakao, Mitsumoto, et al., 2010; Nakao, Takezawa, et al., 2009).

\footnotetext{
$\overline{{ }^{1} \text { Previous ERP }}$ studies by Nakao and colleagues using the occupational choice paradigm did not explicitly test the differences between approachapproach and avoidance-avoidance conflicts and instead conflated decision-making trials from these distinct types of conflict scenarios into one experimental condition. However, the investigation by Di Domenico et al. (2013) did examine the potential differences between these two types of conflict scenarios on an exploratory basis. This study found that participants produced longer reaction times when choosing between two similarly unattractive occupations (i.e., avoidance-avoidance conflicts) relative to when choosing between two similarly attractive occupations (i.e., approach-approach conflicts). The type of high-conflict scenario did not, however, produce differences in MPFC activity. Moreover, need fulfillment did not moderate the effect of high-conflict type on participants' reaction times or MPFC activity. Thus, need fulfillment appears to promote the deployment of people's self-reflective capacities regardless of the type of high-conflict scenario.
} 


\section{Method}

\section{Participants}

The study received approval from the Social Sciences, Humanities, and Education Research Ethics Board at the University of Toronto and was conducted in accordance with the ethical principles of the American Psychological Association (2010). Ninety-one (65 females, 26 males) students from the University of Toronto participated either for course credit in their introductory psychology course or for monetary compensation at a rate of \$15 CAD (\$12.16 USD) per hour. The participants ranged in age from 17 to 25 years $(M=19.68, S D=1.69)$. The study consisted of two laboratory sessions spaced 7 to 10 days apart. In the first session, participants completed the occupational survey and scheduled their appointment for the subsequent session. In the second session, participants first completed the occupational choice task during EEG recording and then a measure of need fulfillment. The need fulfillment measure appeared within a questionnaire battery that is part of a separate and ongoing study examining the relationships between basic psychological needs and other individual difference characteristics.

\section{Self-report measures}

Occupational survey Participants were presented with a list of 107 occupational words (e.g., teacher, writer, politician) and were asked to indicate the extent to which they believed that they might experience personal satisfaction and enjoyment in each occupation as a possible future career. This occupational survey was based on the one utilized by Nakao, Osumi et al. (2009) and was identical to the one used by Di Domenico et al. (2013). Participants were instructed to use their personal preferences as a guide while they rated the items on a scale ranging from 1 (no satisfaction and enjoyment) to 4 (a lot of satisfaction and enjoyment).

Need fulfillment Participants completed the Basic Psychological Needs Scale (BPNS; Gagné, 2003; Ilardi, Leone, Kasser, \& Ryan, 1993). Participants rated 21 statements on a scale from 1 (not at all true) to 7 (definitely true), reflecting the extent to which the needs for competence, relatedness, and autonomy are fulfilled in daily life. Sample items include "Most days I feel a sense of accomplishment from what I do" (competence); "People I interact with on a daily basis tend to take my feelings into consideration" (relatedness); and "I feel like I am free to decide for myself how to live my life" (autonomy). The BPNS contains six items for competence, eight items for relatedness, and seven items for autonomy. To index participants' overall levels of need fulfillment, we first computed the means of the three need subscales and then averaged the subscale scores to obtained an equally-weighted measure of global need fulfillment $(M=5.11, S D=.78, \alpha=.83)$. This global assessment strategy is commonly utilized in SDT research (e.g., Deci et al., 2001; Weinstein \& Ryan, 2010) and is based on SDT's view of competence, relatedness, and autonomy as complementary facilitators of integrative processes (Deci \& Ryan, 2000; Ryan, 1995). In keeping with previous SDT research, participants' general experiences of competence, relatedness, and autonomy were highly correlated: competencerelatedness $r=.51, t(89)=5.65, p<.0001$; competenceautonomy $r=.68, t(89)=8.67, p<.0001$; relatednessautonomy $r=.67, t(89)=8.59, p<.0001$.

\section{The occupational choice task}

For the occupational choice task, we followed identical procedures to those described by Di Domenico et al. (2013) and Di Domenico, Rodrigo, Ayaz, Fournier, and Ruocco (2015). For each participant we constructed a high-conflict approachapproach condition (hereafter APP) in which the nine occupational words that were rated most favorably were used as stimuli; a high-conflict avoidance-avoidance condition (hereafter AVD) in which the nine occupational words that were rated least favorably were used as stimuli; and a low-conflict condition (hereafter LC) in which the word stimuli utilized in the APP and AVD conditions were paired to produce clear differences in preference. To ensure the validity of the experiment, the word sets that we used to construct the APP, AVD, and LC conditions contained at least seven high-preference occupational words with a maximally favorable rating of 4 and at least seven low-preference occupational words with a maximally unfavorable rating of 1 . If needed, the remaining two high- and low-preference occupational words were drawn from those that the participant had respectively rated 3 and 2 in terms of personal preference. When participants supplied multiple occupational words with the same rating, we selected the occupational words that had received the most extreme ratings from an independent samples of students in our piloting $(N=110)$ and previous research (Di Domenico et al., 2013) using occupational survey. Through this laborintensive procedure, we idiographically manipulated the pairing of word stimuli for each participant.

Figure 1 exemplifies the flow of one trial in the occupational choice paradigm. The trials for the APP and AVD conditions were constructed by forming all possible combinations for word pairs among the nine high- and nine low-preference occupational words, respectively. This resulted in a total of 36 trials for each of the APP and AVD conditions. The trials for the LC condition were constructed by joining each of the nine high-preference words with each of the nine low-preference words. This resulted in a total of 81 trials within the LC condition. Altogether, this method for constructing trials yielded a total of 153 trials for each participant (i.e., 36 APP trials +36 


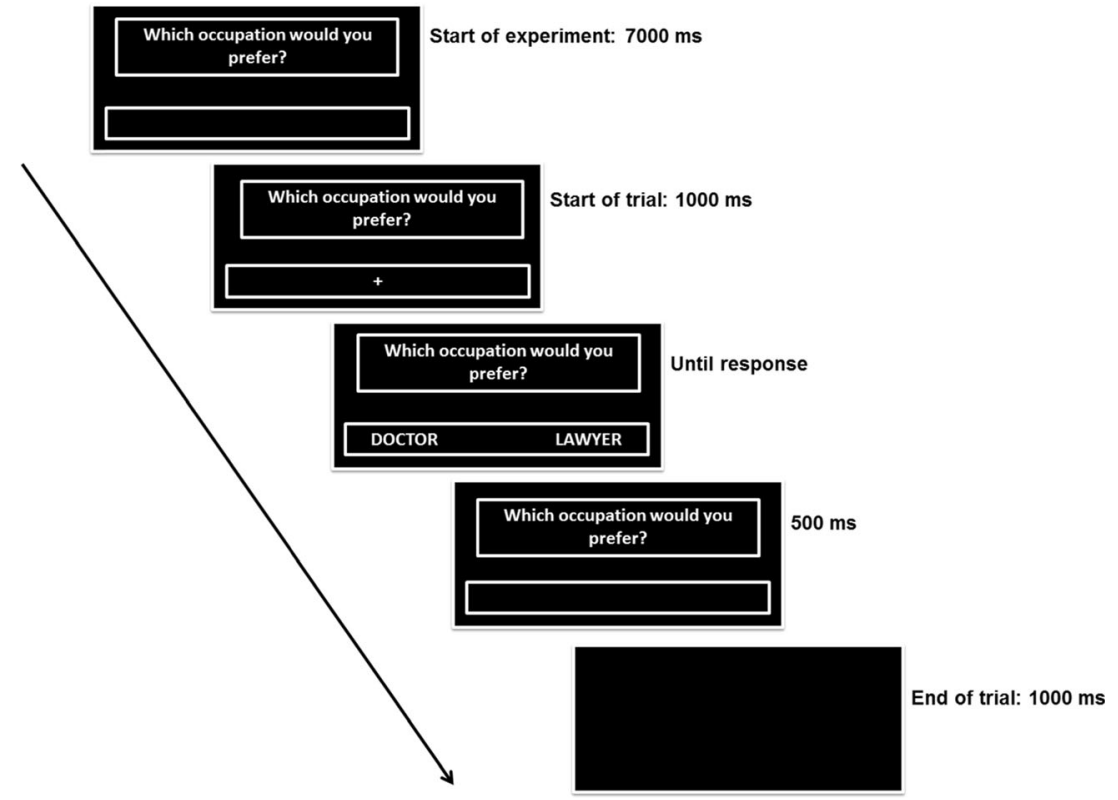

Fig. 1 Flow of one trial in the occupational choice paradigm

AVD trials +81 LC trials). In both the APP and the AVD conditions, each stimulus word appeared a total of eight times. On four trials, each occupational word appeared on the righthand side of the screen. On the other four trials, each occupational word appeared on the left-hand side of the screen. In the LC condition, each stimulus word appeared a total of nine times. Given this odd number of presentations, we randomly selected a high-preference occupational choice word to appear with a low-preference occupational choice word on the righthand side of the screen five times for each participant.

The design of experimental trials was based on the occupational choice task described in Nakao, Mitsumoto, et al. (2010). As shown in Fig. 1, the experiment began with the appearance of the question "Which occupation would you prefer?" on the screen for 7,000 ms. This question was presented in white color against a black background. Beneath this question, there appeared a white rectangle, within which the stimulus words would appear. Each trial began with a 1,000ms presentation of this same display, except with a crosshair fixation in the middle of the rectangle. Then, two stimulus words appeared on the screen within the rectangle. Participants were told that there was no objectively correct or incorrect answer to each question and that they should make their choices using their own personal preferences as a guide. They were instructed to respond as quickly as possible on each trial by pressing one of two keyboard buttons (i.e., 2 or z) using the corresponding index fingers of their right and left hands. The stimulus words remained visible until participants pressed a button to make their choice. Reaction times (RTs) were defined as the time elapsed from the onset of each trial to the registration of participants' corresponding button press. After responses were registered, the stimulus words disappeared, but the rectangle remained visible for another $500 \mathrm{~ms}$. A black screen then appeared for 1,000 ms before the next trial began. The occupational choice task was programmed and administered using E-Prime 2.0 software (Psychology Software Tools, Inc.).

Participants completed the occupational choice task in a dark room in front of a computer monitor and a keyboard. Prior to the beginning of the occupational choice task, instructions were presented on the monitor and read aloud by the experimenter. The experiment did not proceed until participants acknowledged that they understood all the instructions completely. Participants were also given 24 practice trails to familiarize themselves with the task. The word stimuli consigned to the practice trials were those that participants had previously given "medium" preference ratings on the occupational survey. These stimuli were not utilized in the actual experiment. During the experiment, the order in which participants completed trials belonging to APP, AVD, and LC conditions was pseudorandomized with the stipulation that the same occupational word could not be presented on consecutive trials.

\section{Neurophysiological recording protocol}

Continuous electroencephalogram (EEG) during the occupational choice task was recorded from $128 \mathrm{Ag} / \mathrm{AgCl}$ scalp electrodes using a HydroCel Geodesic Sensor Net and Net Station software (Electrical Geodesics, Inc.). Consistent with guidelines recommended by the manufacturer, electrode impedances were kept below $70 \mathrm{k} \Omega$. Recordings were digitized continuously at $512 \mathrm{~Hz}$. The experimental apparatus (i.e., cables, wires, and computer monitor) was shielded and grounded to 
reduce the effects of electrical $(60 \mathrm{~Hz})$ noise in the EEG data. The EEG recordings were first referenced to the average of all electrodes offline and then bandpass filtered from $0.1 \mathrm{~Hz}$ to $150 \mathrm{~Hz}$. Epochs were defined as $400 \mathrm{~ms}$ prior to and $200 \mathrm{~ms}$ subsequent to participant response. The period between $400 \mathrm{~ms}$ and $200 \mathrm{~ms}$ prior to participant response was used for baseline correction.

Following best practice recommendations (Luck \& Gaspelin, in press), the measurement window and electrode sites used in the present study were determined a priori on the basis of previous CN studies (Nakao et al., 2013; Nakao, Mitsumoto, et al., 2010; Nakao, Takezawa, et al., 2009). The $\mathrm{CN}$ was defined as the mean amplitude between $0 \mathrm{~ms}$ and $60 \mathrm{~ms}$ following the participant's response. As shown in Fig. 2, the $\mathrm{CN}$ was measured at four fronto-central electrode sites: $6(\mathrm{FCz}), 12,5$, and $11(\mathrm{Fz})$. Trials with blinks and improper eye fixation behavior were rejected on the basis of vertical and horizontal electrooculogram. An artifact rejection criterion of $\pm 30 \mu \mathrm{V}$ was used at all other scalp sites to reject trials with excessive noise. Channels with corrupted signals or with substantial noise throughout the recording were replaced by interpolation of signals from neighboring electrodes. Across the three experimental conditions and four a priori electrode site locations, $\mathrm{CN}$ data was interpolated for a total of seven participants. Among these seven participants, the number of interpolated trials across the experimental conditions ranged from 1 to $19(M d n=2)$ and the number of interpolated electrode sites across the experimental conditions ranged from 1 to $10(M d n=2)$. The artifact rejection algorithms discarded the recordings of five participants.

The median number of artifact-free trials used to compute $\mathrm{CN}$ amplitudes in the APP, AVD, and LC conditions was 26 , 27 , and 61 , respectively. For each experimental condition, the reliability of the $\mathrm{CN}$ amplitude measured by a single electrode was estimated using a Type III intraclass correlation coefficient (Shrout \& Fleiss, 1979). ${ }^{2}$ Such reliability estimates reflect the correlation that would be expected between two randomly selected electrodes used to measure the $\mathrm{CN}$ in the present study. The single-electrode reliability and corresponding $95 \%$ confidence intervals of the $\mathrm{CN}$ amplitudes in the APP, AVD, and LC conditions were .69 [.60, .77], .71 [.63, .79], and $.73[.65, .80]$, respectively. These reliability coefficients

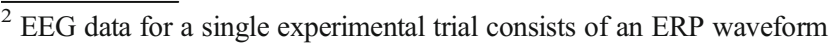
and random noise. Aggregating multiple trials of EEG data into a single averaged waveform (signal averaging) has the effect of increasing the reliability of ERP measurements by cancelling out the random error of individual trials (Luck, 2005). The reliability of an averaged ERP waveform thus reflects whether an adequate number of trials was used to measure that waveform. The reliability of an ERP waveform can be quantified by the correlation (degree of similarity) between two or more measures of the same ERP waveform (e.g., Olvet \& Hajcak, 2009). We capitalized on the fact that we measured the $\mathrm{CN}$ at four electrode sites to assess whether an adequate number of trials was used to measure the $\mathrm{CN}$.
}

indicate that an adequate number of trials was used to measure the $\mathrm{CN}$ amplitudes in each condition.

\section{Data requirements}

To ensure the validity of our experimental manipulations, we followed the methods of Di Domenico et al. (2013) to select the word stimuli for the three decision-making situations. For each participant, valid word stimuli sets consisted of least seven high-preference occupational words with a maximally favorable rating of 4 and at least seven low-preference occupational words with a maximally unfavorable rating of 1 . In regard to the most favored occupations, 55 of the 91 individuals who completed the study provided maximally favorable ratings for at least seven items on the occupational survey. The need fulfillment scores of those 55 participants that provided maximally favorable ratings on the occupational survey did not differ from the scores of those 36 participants that did not provide maximally favorable ratings, $t(64.09)=.72, p=.48$. In the analyses, we excluded the behavioral and EEG data for the APP and LC conditions from the 36 participants who did not provide at least seven maximally favorable ratings in the occupational survey. We nonetheless included the behavioral and EEG data for the AVD condition from these 36 participants because the occupational word stimuli met the previously described data requirements for this condition. In regard to the least favored occupations, 89 of the 91 individuals who completed the study provided maximally unfavorable ratings for at least seven items on the occupational survey. The need fulfillment scores of those 89 participants that provided maximally unfavorable ratings on the occupational survey did not differ from the scores of those two participants that did not provide maximally unfavorable ratings, $t(1.13)=.70, p=.60$. In the analyses, we excluded the behavioral and EEG data for the AVD and LC conditions from the two participants who did not provide at least seven maximally unfavorable ratings in the occupational survey. We nonetheless included the behavioral and EEG data for the APP condition from these two participants because the occupational word stimuli met the previously described data requirements for this condition. ${ }^{3}$

The aforementioned data requirements yielded a total of 9 , 594 trials that were executed from the 91 participants who

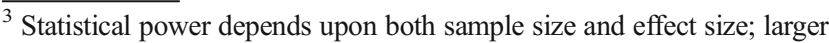
samples and stronger effects yield more statistical power. Because a portion of participants did not provide maximally favorable or unfavorable ratings for the occupational word stimuli, we faced a trade-off between the size of our sample and the strength of our experimental manipulations. The data exclusions described above were undertaken to optimize the statistical power of our study by maximizing the strength of our experimental manipulation. That is, given the choice between either a stronger manipulation with a smaller sample size or a weaker manipulation with a larger sample size, we opted to follow the previous protocols of Di Domenico et al. (2013) to ensure adequate design sensitivity for the experiment.
} 


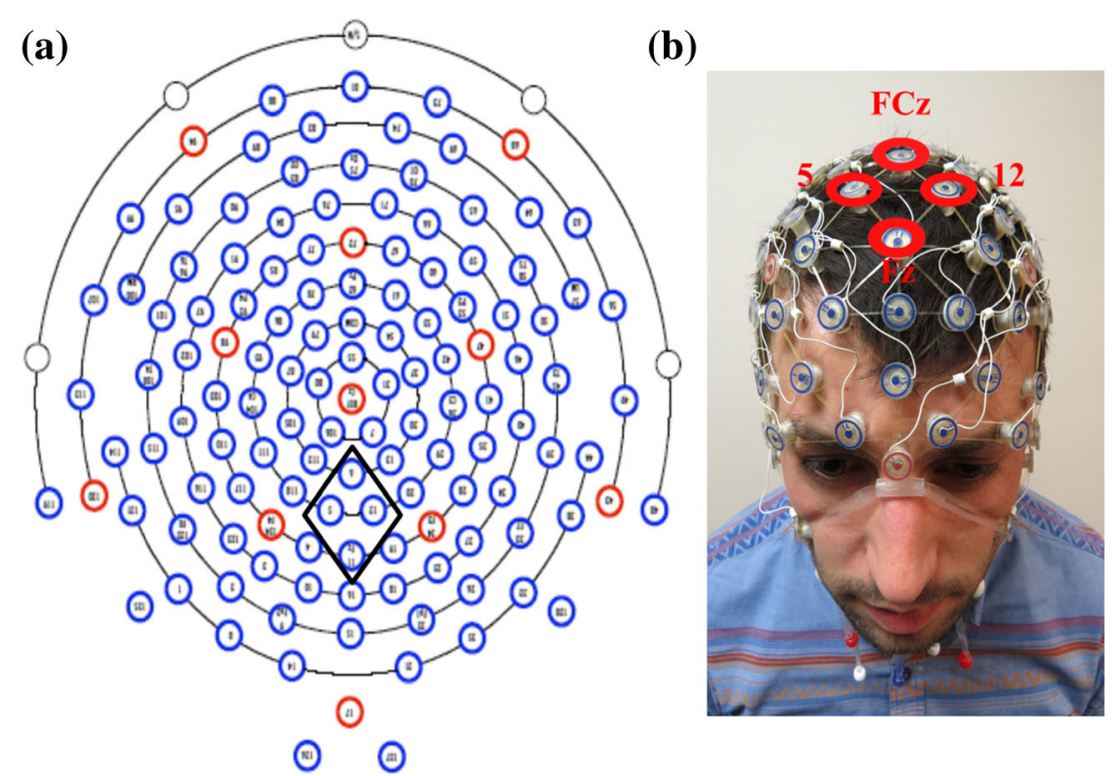

Fig. 2 Layout of the 128-Channel HydroCel Geodesic Sensor Net. (a) The CN was measured at the fronto-central electrode sites 6 (FCz), 12, 5, and 11 (Fz) encased within the black solid lines. (b) Front view of the $\mathrm{CN}$ electrode site locations. (Color figure online.)

completed the study. Because the maximum duration of each trial in the occupational choice task was not fixed and participants' RTs were defined as the time elapsed from the onset of each trial to the registration of their corresponding response, we examined the behavioral data for errant trials. Errant trials were defined as RTs that exceeded the condition means by more than 3.5 standard deviations. On this basis, a total of 118 errant trials were excluded from the analyses (i.e., 27 APP trials, 37 AVD trials, and 54 LC trials). Visual inspection of the EEG recordings revealed that these errant trials were contaminated with eye blinks and motion artifacts and were thus omitted from ERP measurements by the automated rejection algorithms. In total, 9,476 data points from 91 participants were included in the behavioral analyses. Of these 9,476 trails, 1,989 belonged to the APP condition, 3,167 belonged to the AVD condition, and 4,320 belonged to the $\mathrm{LC}$ condition. The median number of trials per participant was 149 and the number of trials per participant was unrelated to participants' levels of need fulfillment, $r=.10, t(89)=.91, p=.37$. Preliminary inspection of the $\mathrm{CN}$ data revealed four extreme observations that exceeded condition means by more than 3.5 standard deviations. We accordingly excluded these extreme observations in our analyses of the $\mathrm{CN}$. We note, however, that including these four observations does not change the significance of the results.

\section{Data analytic approach}

The data were analyzed with multilevel models (Snijders \& Bosker, 2012). Multilevel analyses have been specifically recommended for EEG/ERP data because the technique can account for random effects, effectively handle missing data, and incorporate continuous predictors (Bagiella, Sloan, \& Heitjan, 2000). Within the context of the present study, multilevel models take into account that the experimental trials and neurophysiological recordings are nested within participants and that the data are unbalanced across participants. Variance in the dependent variable is partitioned into within-person (Level 1) and between-person (Level 2) components, allowing predictor terms to be represented at both the level of the experimental trial or electrode (Level 1) and at the level of the participant (Level 2). We examined the Level 1 effect of decisional conflict, the Level 2 effect of need fulfillment, and the Decisional Conflict $\times$ Need Fulfillment cross-level interaction on participants' RTs and CN amplitudes throughout the occupational choice task. The multilevel models were estimated in $R$ (R Development Core Team, 2011) using the multilevel and nlme packages (Bliese, 2009). We estimated random intercept models, nesting the individual RTs and $\mathrm{CN}$ amplitudes within each participant.

In the primary analyses, decisional conflict was treated as a class variable with three levels (APP, AVD, LC) and need fulfillment scores were centered. Following the recommendations of West, Aiken, and Krull (1996), we performed two orthogonal contrasts in our primary analyses to test our a priori hypotheses. The first contrast (C1) compared RTs and CN amplitudes in the APP and AVD conditions with the LC condition. For C1, the APP, AVD, and LC conditions were coded as $1 / 3,1 / 3$, and $-2 / 3$, respectively. Thus, a one-unit change on $\mathrm{C} 1$ represents the mean difference between the high- and lowconflict conditions. The second contrast (C2) compared RTs and $\mathrm{CN}$ amplitudes across the APP and AVD conditions. For C2, the APP, AVD, and LC conditions were coded as $1 / 2,-1 / 2$, and 0 , respectively. Thus, a one-unit change on $\mathrm{C} 2$ represents the mean difference between the APP and AVD conditions. 
Importantly, both the $\mathrm{C} 1$ and $\mathrm{C} 2$ contrast terms respectively represent "difference waves" between low- and high-conflict conditions and between APP and AVD conditions. These difference waves allow us to cancel out the processes common to all decision making and to isolate the effect of decisional conflict across all of the conditions (Luck, 2005). The $\mathrm{C} 1 \times$ Need Fulfillment interaction term examined the extent to which a difference between the high- and low-conflict conditions was moderated by participants' level of need fulfillment. The $\mathrm{C} 2 \times$ Need Fulfillment interaction term examined the extent to which a difference between the APP and AVD conditions was moderated by participants' level of need fulfillment.

We employed a step-up hierarchical procedure to estimate a series of progressively complex models. The $\mathrm{C} 1$ and $\mathrm{C} 2$ contrast terms were entered at Step 1. The conditional effect of need fulfillment and the $\mathrm{C} 1 \times$ Need Fulfillment and $\mathrm{C} 2 \times$ Need Fulfillment interaction terms were entered at Step 2. All models were estimated using the method of maximum likelihood, an unstructured covariance matrix, and the "betweenwithin" method of estimating degrees of freedom (Schluchter $\&$ Elashoff, 1990). Chi-square difference tests were utilized to formally examine the incremental fit of more complex models in the prediction of RTs and CN amplitudes (Snijders \& Bosker, 2012). The equations for the complete multilevel model are detailed below. At Level 1:

$C N_{i j}=\beta_{0 j}+\beta_{1 j} C 1_{i j}+\beta_{2 j} C 2_{i j}+e_{i j}$,

where $\beta_{0 j}$ represents the model intercept, $\beta_{1 j}$ represents the slope of the $\mathrm{C} 1$ contrast term, $\beta_{2 j}$ represents the slope of the $\mathrm{C} 2$ contrast term, and $e_{i j}$ represents the random errors of prediction. At The Level 2 equations for $\mathrm{CN}$ amplitudes were as follows:

$\beta_{0 j}=\gamma_{00}+\gamma_{01} N F_{j}+u_{0 j}$,

$\beta_{1 j}=\gamma_{10}+\gamma_{11} N F_{j}$

$\beta_{2 j}=\gamma_{20}+\gamma_{21} N F_{j}$,

where $\gamma_{00}$ represents the overall model intercept, $\gamma_{01}$ represents the slope between $\mathrm{CN}$ amplitudes and $N F$ (need fulfillment), $\gamma_{10}$ and $\gamma_{20}$, respectively, represent the overall slopes of the $\mathrm{C} 1$ and $\mathrm{C} 2$ contrast terms, $\gamma_{11}$ and $\gamma_{21}$, respectively, represent the slopes between the $\mathrm{C} 1$ and $\mathrm{C} 2$ contrast terms and need fulfillment, and $u_{0 j}$ represents random deviations from the overall intercept. Equations analogous to those above were specified for RTs.

\section{Results}

\section{Behavioral analyses}

The results of the behavioral analyses are summarized in Table 2. At Step 1, the model reduced the prediction error of
RT by a moderate amount both at the level of the trial (Level 1 ), $\mathrm{R}_{\text {Level } 1}^{2}=.15$, and at the level of the participant (Level 2), $\mathrm{R}_{\text {Level } 2}^{2}=.20$. Consistent with previous studies using the occupational choice task (Nakao et al., 2013; Nakao, Mitsumoto, et al., 2010; Nakao, Takezawa, et al., 2009), and indicative of a successful experimental manipulation, the $\mathrm{C} 1$ contrast term at Step 1 revealed that participants had longer RTs in the high-relative to low-conflict conditions, on average taking $357.50 \mathrm{~ms}$ longer to respond to trials in the highconflict conditions. Consistent with the results of $\mathrm{Di}$ Domenico et al. (2013) and with previous research suggesting that avoidance-avoidance conflicts are more difficult to resolve than approach-approach conflicts, the $\mathrm{C} 2$ contrast term at Step 1 revealed that participants had longer RTs in the AVD condition relative to the APP condition, on average taking $259.73 \mathrm{~ms}$ longer to respond to trials in the AVD condition. A chi-square difference test indicated that the model at Step 2 fit the data significantly better than the simpler model at Step $1, \Delta \chi^{2}(3)=10.02, p=.018$, though it produced similar reductions of prediction error at both Level $1, \mathrm{R}_{\text {Level } 1}^{2}=.15$, and Level 2, $\mathrm{R}_{\text {Level } 2}^{2}=.20$. Consistent with the results of Di Domenico et al. (2013), the $\mathrm{C} 1 \times$ Need Fulfillment interaction term at Step 2 revealed that need fulfillment significantly moderated the effect of decisional conflict (low- relative to high-conflict) on individuals' RT, though the $\mathrm{C} 2 \times$ Need Fulfillment interaction term did not reach conventional levels of statistical significance (i.e., $p<.05$ ). To compare the parameter estimates of the present analyses with those of $\mathrm{Di}$ Domenico et al. (2013), we list the $95 \%$ confidence intervals of the unstandardized regression coefficients from the current study and the previous study in the rightmost columns of Table 2. As can be seen in Table 2, the confidence intervals of the present study overlap with the corresponding estimates reported by Di Domenico et al. (2013) and therefore indicate a replication of the previously reported effects.

To begin our examination of the significant $\mathrm{C} 1 \times$ Need Fulfillment interaction term, we plotted and examined the simple slopes of the $\mathrm{C} 1$ contrast term at high $(+1 S D)$ and low (-1 $S D$ ) levels of need fulfillment (Aiken \& West, 1991). The interaction is illustrated in Fig. 3. The simple effect of decisional conflict was more pronounced among participants reporting higher need fulfillment $(+1 S D), b=$ 384.72, $S E=16.13, t(9,381)=23.85, p<.0001$, than among participants reporting lower need fulfillment $(-1$ $S D), b=325.66, S E=17.46, t(9,381)=18.65, p<$ .0001 . These unstandardized regression coefficients signify that participants reporting higher need fulfillment on average took $384.72 \mathrm{~ms}$ longer to respond to individual trials in the APP and AVD conditions relative to the LC condition, but that those reporting lower need fulfillment on average only took $325.66 \mathrm{~ms}$ longer to respond to individual trials in the APP and AVD conditions relative to the $\mathrm{LC}$ condition. 
Table 2 Multilevel analyses of the effect of decisional conflict on reaction time (ms) as moderated by need fulfillment

\begin{tabular}{|c|c|c|c|c|c|c|}
\hline & Predictors & $b(S E)$ & $d f$ & $p$ value & $95 \% \mathrm{CI}$ & $95 \%$ CI from Di Domenico et al. (2013) \\
\hline \multirow[t]{3}{*}{ Step 1} & Intercept & $1379.21(41.98)$ & 9383 & $<.0001$ & {$[1296.94,1461.48]$} & {$[1167.89,1325.86]$} \\
\hline & $\mathrm{C} 1$ & $357.50(11.51)$ & 9383 & $<.0001$ & {$[334.95,380.06]$} & {$[350.00,391.49]$} \\
\hline & $\mathrm{C} 2$ & $-259.73(.16 .69)$ & 9383 & $<.0001$ & {$[-292.43,-227.02]$} & {$[-192.14,-131.79]$} \\
\hline \multirow[t]{3}{*}{ Step 2} & Need fulfillment & $-60.36(54.62)$ & 89 & .272 & {$[-168.86,48.13]$} & {$[-51.35,142.12]$} \\
\hline & $\mathrm{C} 1 \times$ Need fulfillment & $38.08(15.76)$ & 9381 & .016 & {$[7.19,68.97]$} & {$[19.79,67.76]$} \\
\hline & $\mathrm{C} 2 \times$ Need fulfillment & $-41.30(22.86)$ & 9381 & .071 & {$[-86.10,3.51]$} & {$[-27.58,42.40]$} \\
\hline \multicolumn{7}{|c|}{ Correlations of fixed effects: } \\
\hline & Intercept & $\mathrm{C} 1$ & $\mathrm{C} 2$ & \multicolumn{2}{|c|}{ Need fulfillment } & $\mathrm{C} 1 \times$ Need fulfillment \\
\hline $\mathrm{C} 1$ & -.004 & & & & & \\
\hline $\mathrm{C} 2$ & .071 & .009 & & & & \\
\hline Need fulfillment & -.004 & .008 & -.013 & & & \\
\hline $\mathrm{C} 1 \times$ Need fulfillment & .007 & -.079 & .001 & -.013 & & \\
\hline $\mathrm{C} 2 \times$ Need fulfillment & -.012 & .001 & -.077 & .094 & & .012 \\
\hline
\end{tabular}

The models were estimated using the method of maximum likelihood, an unstructured covariance matrix, and the between-within method of estimating degrees of freedom. At Step 1, SD $D_{\text {Intercept }}=394.14$ and $S D_{\text {residual }}=520.42$. At Step 2, $S D_{\text {Intercept }}=394.23$ and $S D_{\text {residual }}=520.14$. C1 compared the unweighted means of the LC condition and the APP and AVD conditions. C2 compared the unweighted means of the APP and AVD conditions. The models were estimated with 9,476 data points from 91 individuals; $95 \% \mathrm{CI}=95 \%$ confidence intervals of effect-size estimates for a similar analysis reported in Di Domenico et al. (2013)

To further investigate the significant $\mathrm{C} 1 \times$ Need Fulfillment interaction term, we examined the simple slopes of need fulfillment at low- and high-levels of decisional conflict. The simple effect of need fulfillment was not significant in either the LC condition, $b=-82.14, S E=57.19, t(89)=-1.44, p=$ .15 , or in the APP and AVD conditions, $b=-43.19, S E=$ $56.22, t(89)=-.77, p=.45$. These unstandardized regression coefficients signify that although need fulfillment on average predicted slightly shorter RTs within both low- and highconflict conditions (82.14 ms and $43.19 \mathrm{~ms}$, respectively), these shorter reaction times were not significantly different from zero. These results replicate the interaction between decisional conflict and need fulfillment in the prediction of participants' RT reported by Di Domenico et al. (2013) and further support the idea that need fulfillment promotes a more flexible and adaptive deployment of attentional resources during the regulation of decisional conflicts.

\section{CN analyses}

Figure 4 presents the grand-averaged ERPs elicited by the occupational choice task in the LC, APP, and AVD conditions. In all conditions, a pronounced negativity that peaked immediately after participants executed a response (i.e., the $\mathrm{CN}$ ) was observed across the four electrode sites of interest. Figure 5 shows that the voltage topographies across the 0 to

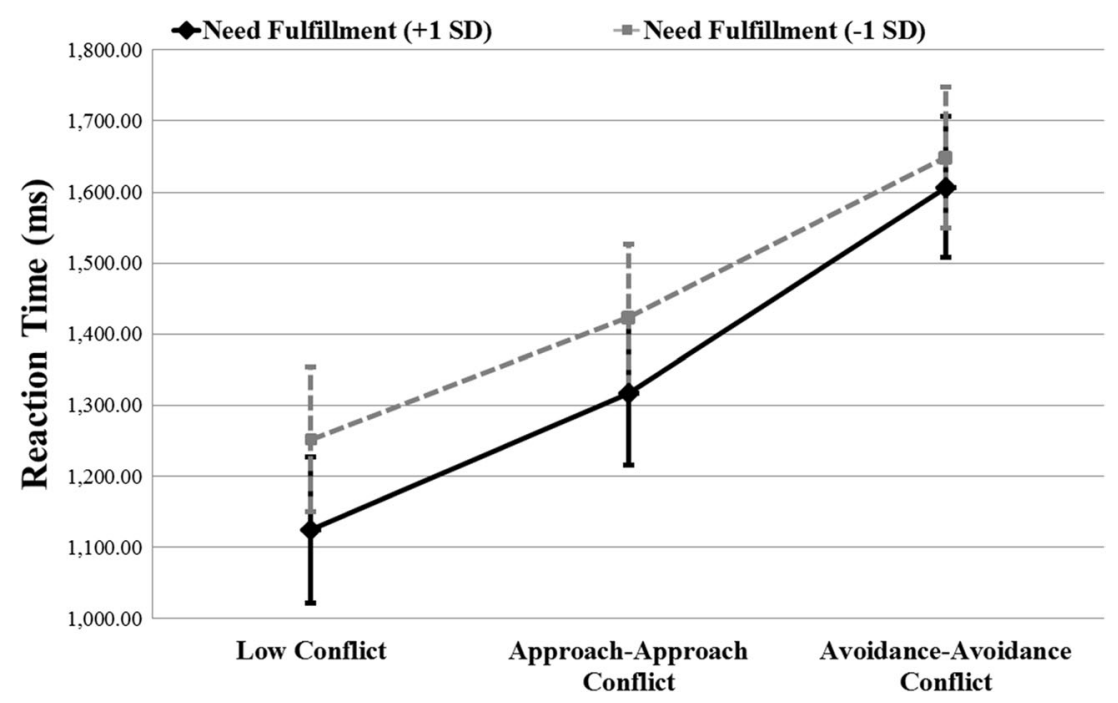

Fig. 3 Predicted reaction time across levels of decisional conflict and need fulfillment. Error bars represent $90 \%$ confidence intervals 

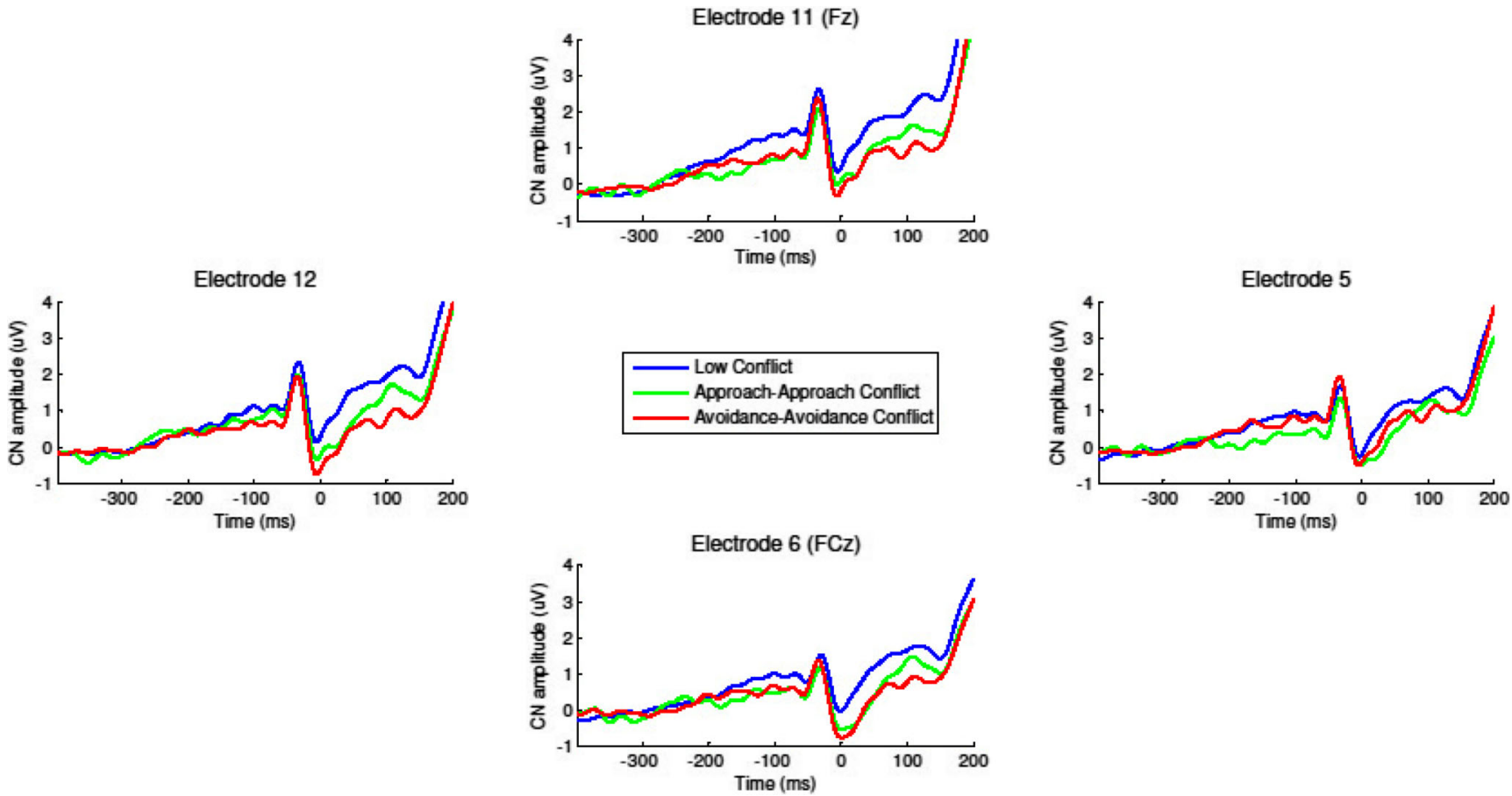

Fig. 4 Grand-averaged ERPs elicited by the occupational choice task in the APP, AVD, and LC conditions across electrode sites 6 (FCz), 12, 5, and $11(\mathrm{Fz})$. The period between $-400 \mathrm{~ms}$ and $-200 \mathrm{~ms}$ was used for baseline correction. $\mathrm{CN}$ amplitudes were calculated over the $60 \mathrm{~ms}$ time period following the onset of participants' response at $0 \mathrm{~ms}$. For enhanced clarity, the ERP waveforms in this figure were digitally low-pass filtered at $30 \mathrm{~Hz}$ (Luck, 2005). (Color figure online.)

\& Makeig, 2004). Clustering of source dipoles estimated from all participants revealed centroid dipoles (see Fig. 6) that were present in each of the three experimental conditions and locat-

ed in areas approximately consistent with the ACC, a region
60 ms measurement window evidenced a clear fronto-central distribution. A source localization procedure adopting independent components analysis and a four-shell spherical head model was conducted using the EEGLAB Toolbox (Delorme
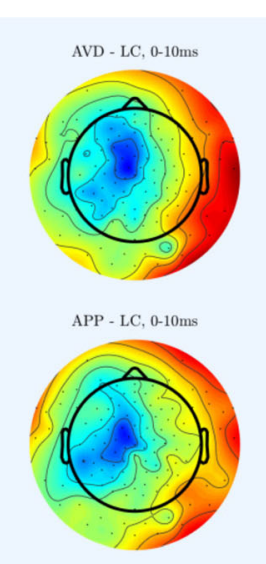

AVD - APP, 0-10ms

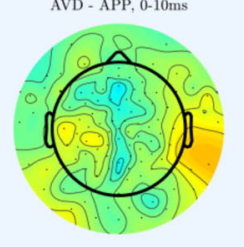

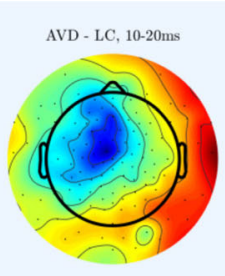
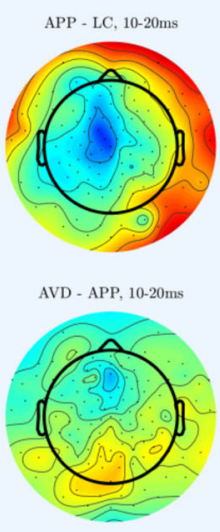
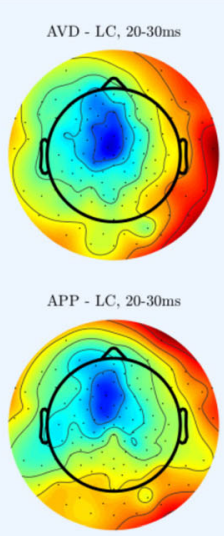

AVD - APP, 20-30ms

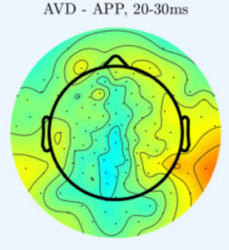

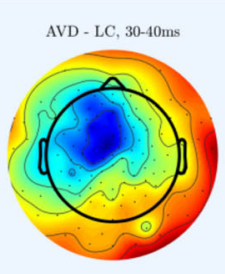

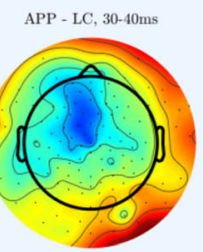

AVD - APP, 30-40ms

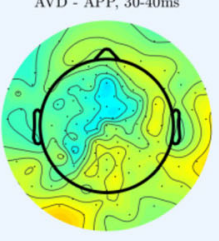

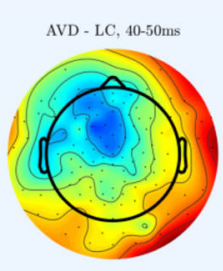

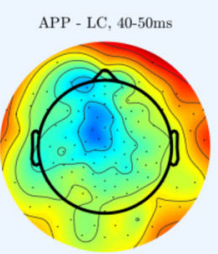

AVD - APP, 40-50ms

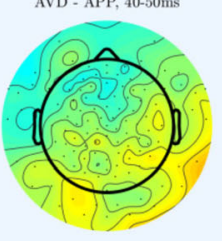

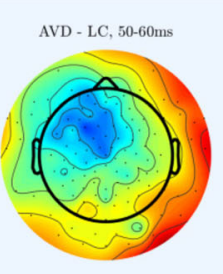

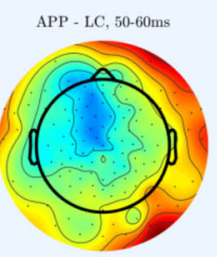

AVD - APP, 50-60ms

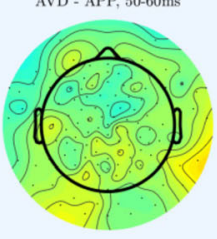

Fig. 5 Voltage topographies of the response-locked CN difference waves over the $60 \mathrm{~ms}$ time period following the onset of participants' response at $0 \mathrm{~ms}$. (Color figure online.) 


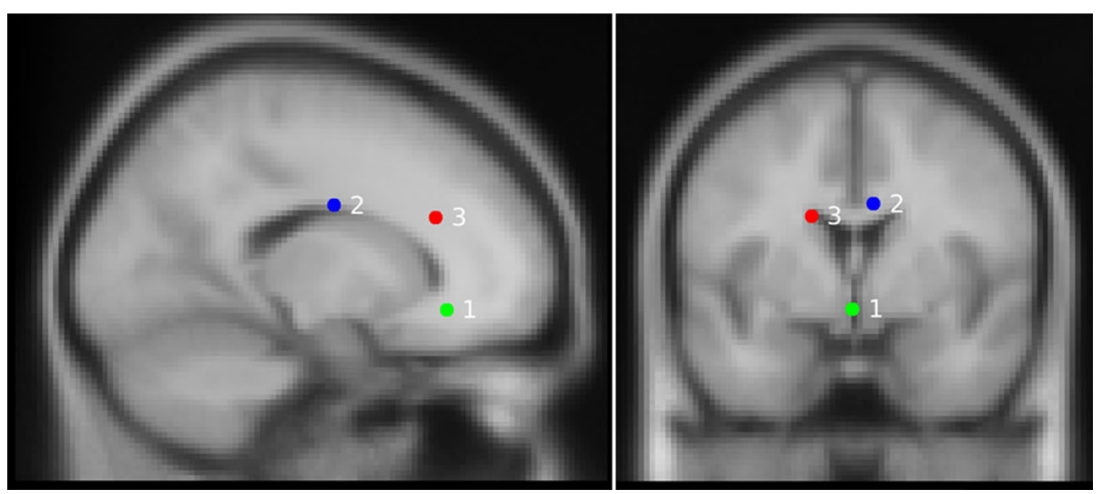

Fig. 6 Dipole source localization confirmed the contribution of the ACC in generating the CNs. Dipole centroids 1 (green; $x=-1, y=31, z=-9$ ), 2 (blue; $x=7, y=-10, z=29$ ), and 3 (red; $x=-15, y=27, z=-24$ ), respectively, accounted for $58.9 \%, 24.6 \%$, and $16.5 \%$ of the signal variance approximately originating in the ACC. The dipole centroid locations are expressed in Montreal Neurological Institute coordinates. (Color figure online.)

pronounced differences in $\mathrm{CN}$ amplitudes between the high- and low-conflict situations, $b=-1.03, S E=.16$, $t(654)=-6.35, p<.0001$, those reporting lower need fulfillment exhibited weaker differences in $\mathrm{CN}$ amplitudes between the high- and low-conflict situations, $b=-.36, S E$ $=.19, t(654)=-1.96, p=.050$. Contrary to our second hypothesis, the $\mathrm{C} 2 \times$ Need Fulfillment interaction term indicated that need fulfillment did not moderate the difference in CN amplitude between the APP and AVD conditions. To more precisely examine how need fulfillment moderated neurophysiological responses across the lowand high-conflict conditions, we separately tested if need fulfillment moderated differences in $\mathrm{CN}$ amplitudes between the LC condition and both the AVD and APP conditions.

Figure 7 shows the predicted $\mathrm{CN}$ amplitudes across the three conflict conditions at high $(+1 S D)$ and low $(-1 S D)$ levels of need fulfillment. In keeping with our prediction, differences in $\mathrm{CN}$ amplitudes between the AVD condition and the LC condition varied as a function of need fulfillment, $b=-.52, S E=.19, t(654)=-2.80, p=.005$. Specifically, participants reporting higher need fulfillment exhibited larger $\mathrm{CN}$ amplitudes in the AVD condition relative to the LC condition, $b=-1.25, S E=.18, t(654)=-$ $6.78, p<.0001$, compared to those reporting lower need fulfillment, $b=-.44, S E=.21, t(654)=-2.06, p=.039$. To a lesser extent, differences in $\mathrm{CN}$ amplitudes between the APP condition and the LC condition also varied as a function of need fulfillment, $b=-.33, S E=.19, t(654)=$ $1.73, p=.085$. Participants reporting higher need fulfillment tended to exhibit larger $\mathrm{CN}$ amplitudes in the APP condition relative to the LC condition, $b=-.80, S E=.19$, $t(654)=-4.27, p<.0001$, compared to those reporting lower need fulfillment, $b=-.29, S E=.22, t(654)=$ $1.36, p=.175$. Overall, these results support the hypothesis that need fulfillment increases people's receptivity to and processing of events that challenge their abilities to high-conflict conditions. Specifically, while partici pants reporting higher need fulfillment exhibited 
Table 3 Multilevel analyses of the effect of decisional conflict on $\mathrm{CN}$ amplitude $(\mu \mathrm{V})$ as moderated by need fulfillment

\begin{tabular}{|c|c|c|c|c|c|}
\hline & Predictors & $b(S E)$ & & $d f$ & $p$ value \\
\hline \multirow[t]{3}{*}{ Step 1} & Intercept & $.36(.18)$ & & 656 & .051 \\
\hline & $\mathrm{C} 1$ & $-.74(.12)$ & & 656 & $<.0001$ \\
\hline & $\mathrm{C} 2$ & $.31(.14)$ & & 656 & .022 \\
\hline \multirow[t]{3}{*}{ Step 2} & Need fulfillment & $.02(.24)$ & & 84 & .951 \\
\hline & $\mathrm{C} 1 \times$ Need fulfillment & $-.43(.16)$ & & 654 & .010 \\
\hline & $\mathrm{C} 2 \times$ Need fulfillment & $.20(.19)$ & & 654 & .296 \\
\hline \multicolumn{6}{|c|}{ Correlations of fixed effects: } \\
\hline & Intercept & $\mathrm{C} 1$ & $\mathrm{C} 2$ & Need fulfillment & $\mathrm{C} 1 \times$ Need fulfillment \\
\hline $\mathrm{C} 1$ & -.081 & & & & \\
\hline $\mathrm{C} 2$ & .130 & .025 & & & \\
\hline Need fulfillment & -.039 & .029 & -.042 & & \\
\hline $\mathrm{C} 1 \times$ Need fulfillment & .028 & -.143 & -.005 & -.101 & \\
\hline $\mathrm{C} 2 \times$ Need fulfillment & -.039 & -.004 & -.134 & .172 & .023 \\
\hline
\end{tabular}

The models were estimated using the method of maximum likelihood, an unstructured covariance matrix, and the between-within method of estimating degrees of freedom. At Step 1, SD Intercept $=1.58$ and $S D_{\text {residual }}=1.38$. At Step 2, $S D_{\text {Intercept }}=1.56$ and $S D_{\text {residual }}=1.38$. C1 compared the unweighted means of the LC condition and the APP and AVD conditions. C2 compared the unweighted means of the APP and AVD conditions. The models were estimated with 744 data points from 86 individuals

make efficient, self-congruent choices, and indicate that this effect is most pronounced in the comparison of lowconflict and avoidance-avoidance conflict situations. ${ }^{4}$

\section{Discussion}

Basic psychological needs define the experiences that facilitate people's integrative capacities to develop and act from a coherent sense of self (Chirkov et al., 2011; Deci \& Ryan, 2000; Ryan, 1995; Sheldon, 2014; Vansteenkiste \& Ryan, 2013). Although a large body of research has examined the experiential and behavioral properties of self-coherence, research has only begun to examine the neurophysiological processes that constitute the integrative functions of need fulfillment. The results of the present study found that people reporting higher need fulfillment exhibited larger $\mathrm{CN}$ amplitudes when making decisions in high- relative to low-conflict situations, particularly in avoidance-avoidance situations. A key distinction between high- and low-conflict situations is the degree to which the content of the available choice selections fit people's preferences and, therefore, the degree to which

\footnotetext{
${ }^{4}$ Given that the number of trials used to compute $\mathrm{CN}$ amplitudes varied across the experimental conditions, we conducted the $\mathrm{CN}$ analyses a second time using weighted contrast codes (West et al., 1996). Specifically, we weighted the $\mathrm{C} 1$ and $\mathrm{C} 2$ contrast terms by the number of trials used to compute the $\mathrm{CN}$ in each condition. This analysis indicated significant main effects and interactions similar to the results above and thus suggests that the present findings were not artifactually driven by the unequal number of trials used to compute the $\mathrm{CN}$ across the conditions.
}

people's existing self-knowledge representations can be applied to efficiently select a behavioral response. These results thus provide support for the idea that need fulfillment is associated with greater receptivity to situations that signal a demand to update existing self-knowledge representations in the service of efficient, self-congruent decision making.

The present study benefitted by adapting an occupational choice paradigm that previously established the $\mathrm{CN}$ as a measure of response conflict during personal decision making (Nakao et al., 2013; Nakao, Mitsumoto, et al., 2010; Nakao, Takezawa, et al., 2009). We replicated the previously reported findings of larger $\mathrm{CN}$ amplitudes and longer reaction times in high- relative to low-conflict situations, and dipole source localization found support for the idea that the CNs were generated in the ACC (Nakao, Osumi, et al., 2010; Nakao et al., 2012). Furthermore, by differentiating approach-approach and avoidance-avoidance conflicts, the present study afforded a more nuanced examination of the $\mathrm{CN}$. Consistent with the classic decision-making literature (Lewin, 1935; N. E. Miller, 1944, 1959), we found that the avoidance-avoidance conflicts produced the largest $\mathrm{CN}$ amplitudes and that the $\mathrm{CN}$ amplitudes produced by approach-approach conflicts also significantly differed from those produced in low-conflict scenarios.

Contrary to one of our hypotheses, need fulfillment did not moderate $\mathrm{CN}$ amplitudes across the approach-approach and avoidance-avoidance situations. A straightforward possibility for this unexpected finding is that we may have underestimated the degree of decisional conflict experienced by highly need-fulfilled people in approach-approach 


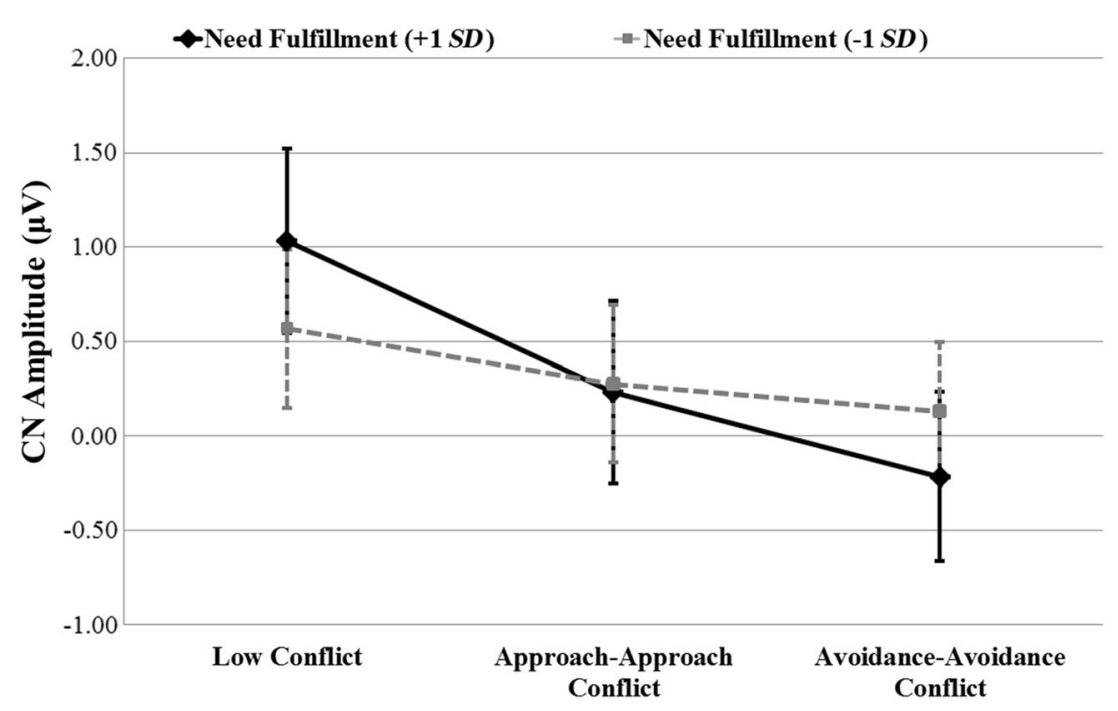

Fig. 7 Predicted CN amplitudes across levels of decisional conflict and need fulfillment. Error bars represent $90 \%$ confidence intervals

situations. Consistent with this possibility, the behavioral results of the present study and of the study by Di Domenico et al. (2013) found that need fulfillment does not moderate reaction times across approach-approach and avoidanceavoidance situations. This unexpected finding is also consistent with Di Domenico et al.'s (2013) previous finding that need fulfillment predicted greater MPFC activity in high- relative to low-conflict situations but did not moderate MPFC activity across the two types of high-conflict situations. Need fulfillment thus appears to promote people's responsiveness to decisional conflicts, regardless of the type of high-conflict scenario. Although Lewin (1935) and N. E. Miller (1944, 1959) long ago explicated the differences between approachapproach and avoidance-avoidance conflicts, the difference between these types of decision-making situations is relatively understudied in neuroscience. We hope that our differentiation of these two types of decisional conflict to examine the $\mathrm{CN}$ encourages others to investigate how people respond to varied types of personal decision-making situations.

An important task for future research will be to more closely examine the motivational dynamics associated with the discriminating pattern of $\mathrm{CN}$ amplitudes evidenced by individuals experiencing higher need fulfillment. A distinct possibility is that experiences of competence, relatedness, and autonomy motivate people to contend with the anxious uncertainty imposed by decisional conflicts (Hirsh et al., 2012; Schwartz, 2000). On the one hand, people who experience higher need fulfillment may perceive decisional conflicts as challenges that can be overcome (cf. Blascovich \& Mendes, 2000; Mendes, 2016) and perhaps even as opportunities for selfexploration (Di Domenico et al., 2013). Consistent with this idea, need fulfillment is known to foster non-defensive, approach-related coping processes that enhance the integration of experiences that are incongruous or otherwise threatening to one's sense of self (Vansteenkiste \& Ryan, 2013; Weinstein et al., 2013). On the other hand, people who experience lower need fulfillment may perceive decisional conflicts as threats to the existing organization of their self-knowledge and may thus defensively avoid or be less willing to engage with such experiences (cf. Rogers, 1961). Such a defensive and compartmentalized style of regulation would help account for the present finding that individuals reporting lower need fulfillment evidenced a pattern of $\mathrm{CN}$ amplitudes that less sharply differentiated the decision-making situations. Importantly, challenge and threat are motivational states with distinct patterns of cardiovascular reactivity (Blascovich and Mendes, 2000; Mendes, 2016). Future research ought to capitalize on previous psychophysiological findings to more precisely characterize how need fulfillment modulates people's engagement with and processing of conflict-ridden experiences.

The results of the current study also bear important implications for research on the development of well-internalized forms of behavioral regulation, an important aspect of selfcoherent functioning. Within SDT, internalization refers to the process whereby an individual accepts a sociocultural value, practice, or behavioral script; brings it into harmony with other aspects of his or her identity; and thereby transforms it into a self-regulation. Well-internalized behavioral regulations form the basis for autonomous motivation, which is evidenced when one experiences a sense of volition and personal endorsement of goal-directed activities. Autonomous motivation, in turn, is reliably associated with enhanced performance and psychological health across a wide variety of applied domains and developmental epochs (e.g., Chirkov et al., 2011; Deci \& Ryan, 2008). Like all integrative processes, however, internalization depends on ambient supports for the fulfillment 
of basic psychological needs (Deci \& Ryan, 2000). Social contexts that afford people the fulfillment of the basic psychological needs foster the development of autonomous motivation for the activities pursued therein (e.g., Deci \& Ryan, 2000). Suboptimal forms of motivation arise when socializing agents (e.g., parents, teachers, workplace supervisors) fail to provide adequate opportunities for those in their care to fulfill their psychological needs.

Although the positive influence of need fulfillment on the development of autonomous motivation is wellestablished in both basic and applied research, the precise processes through which need fulfillment facilitates internalization have yet to be empirically delineated. The present results encourage us to speculate that one way that need fulfillment may promote internalization is by increasing people's awareness and systematic processing of the conflict-ridden experiences that the internalization process may sometimes entail. Internalizing or "taking in" a novel behavioral regulation into one's sense of self may sometimes require a reprioritization of one's goals and deeper insight about one's core values, self-reflective operations that entail the sorting out of emergent conflicts (e.g., Carver \& Scheier, 1998; McAdams, 2013; Sheldon, 2014). As Deci and Ryan (1985, p. 130) put it, "transforming an outer regulation into an inner one requires that one reorganize one's capacities and propensities, and it may require that one shift one's perspective or values. Such modifications, like all developmental acquisitions, require active work." Thus, by amplifying people's responses to the potential conflicts between newly constructed and preexisting self-regulatory schemes, need fulfillment may help the development of integrative value frameworks that enable people to more autonomously regulate their goal-directed activities.

Some support for the aforementioned idea comes from the widely used counselling style called motivational interviewing (MI; W. R. Miller \& Rollnick, 2002), which has been described as a "client-centered, directive method for enhancing intrinsic [or more exactingly, autonomous] motivation to change by exploring and resolving ambivalence" (p. 25). MI is used in the treatment of many problem behaviors (e.g., alcohol and drug abuse, binging and purging, gambling). MI practitioners begin with the acknowledgement that many clients enter counselling and psychotherapy with conflicting motivations: "They want to drink (or smoke, or purge, or gamble), and they don't want to" (p. 14). To help clients work through decisional impasse and scaffold their personal considerations for positive behavioral change, an explicit principle in motivational interviewing is to develop discrepancy, that is, "to create and amplify, from the clients' perspective, a discrepancy between present behaviors and his or her broader goals and values" (p. 38). By helping clients to become more aware of the conflict between their life goals and values, on the one hand, and their current problem behaviors, on the other, MI practitioners help clients to make more volitional and wholehearted decisions concerning change. Of course, developing discrepancy is most effective in fostering autonomous motivation for positive change when employed within a need supportive context, a point emphasized by SDT practitioners and MI experts alike (Markland, Ryan, Tobin, \& Rollnick, 2005; W. R. Miller \& Rollnick, 2012; Vansteenkiste, Williams, \& Resnicow, 2012).

\section{Limitations}

Future research should address three key limitations of the present study: the restricted experimental manipulation of decisional conflict, the selective population from which the present sample was drawn, and the cross-sectional design.

We expanded the occupational choice paradigm of Nakao and colleagues to examine three distinct types of decision-making situations (i.e., low conflict, approachapproach conflict, and avoidance-avoidance conflicts), but the present study did not examine a fourth type of conflict scenario: double approach-avoidance conflicts (Lewin 1935; N. E. Miller 1944, 1959). In such situations, an individual must choose between two or more alternatives that each possess attractive and unattractive characteristics. Such decision scenarios are believed to produce the highest levels of indecision and are believed to more closely approximate decisional conflict in naturalistic settings (e.g., Dollard \& Miller, 1950; W. R. Miller \& Rollnick, 2002). Thus, an important task for future research will be to operationalize double approachavoidance conflicts because such paradigms could be instrumental for furthering our understanding of the $\mathrm{CN}$ and the integrative function of need fulfillment.

Given our use of the occupational choice paradigm, we tested our hypotheses on a sample of university students. Occupational choice tasks are highly suited to this population because career decisions are meaningful and salient to many emerging adults (Arnett, 2000). Nonetheless, different psychosocial concerns become salient at different points in the life span (Erikson, 1950, 1968). Future research is thus required to test the generalizability of the relationship between need fulfillment and responsiveness to decisional conflict.

Another limitation of the present study was its crosssectional design. The main hypothesis was that need fulfillment is associated with enhanced neurophysiological responsiveness to situations in which self-knowledge representations cannot be used to efficiently guide decision making, situations that test people's readiness to revise their self-knowledge representations in the service of self-coherence. Although this hypothesis was supported, the cross-sectional design 
precluded the possibility for us to test whether this heightened responsiveness to decisional conflict is predictive of subsequent revisions to people's self-knowledge representations. Longitudinal designs will be required to test whether conflict-related brain activity during decision making mediates the relation between need fulfillment and self-knowledge schema elaboration.

\section{Conclusion}

The present study built upon previous research (Di Domenico et al., 2013; Nakao et al., 2013; Nakao, Mitsumoto, et al., 2010; Nakao, Takezawa, et al., 2009) to examine the relationship between people's levels of need fulfillment and their neurophysiological responsiveness to decisional conflicts. Basic psychological needs and integrative processes have been traditionally examined along experiential and behavioral lines of inquiry. However, the tools of neuroscience promise new insights that psychological analyses alone do not afford. The present research may therefore serve as a point of reference for future studies coordinating empirical efforts across these two levels of analysis and help furnish new opportunities for further elucidating the nature of self-coherence.

Acknowledgments The authors express their appreciation to Faiza Ahmed, Mengxi Dong, and Mesaaba Correia for their contributions to the collection of these data. The authors are also grateful to Michael Inzlicht, Geoff MacDonald, and Richard M. Ryan for their generous and helpful inputs on earlier drafts of this manuscript. The first author was supported in this research by a doctoral fellowship from the Social Sciences and Humanities Research Council of Canada.

\section{References}

Aiken, L. S., \& West, S. G. (1991). Multiple regression: Testing and interpreting interactions. Thousand Oaks, CA: Sage.

American Psychological Association. (2010). Ethical principles of psychologists and code of conduct. Retrieved from http://apa.org/ethics/ code/index.aspx

Anderson, C. J. (2003). The psychology of doing nothing: Forms of decision avoidance result from reason and emotion. Psychological Bulletin, 129, 139-167. doi:10.1037/0033-2909.129.1.139

Arkoff, A. (1957). Resolution of approach-approach and avoidanceavoidance conflicts. Journal of Abnormal and Social Psychology, 55, 402-404. doi:10.1037/h0043956

Arnett, J. J. (2000). Emerging adulthood: A theory of development from the late teens through the twenties. American Psychologist, 55, 469480. doi:10.1037//0003-066X.55.5.469

Bagiella, E., Sloan, R. P., \& Heitjan, D. F. (2000). Mixed-effects models in psychophysiology. Psychophysiology, 37, 13-20. doi:10.1017/ S0048577200980648

Blair, K., Marsh, A. A., Morton, J., Vythilingam, M., Jones, M., Mondillo, K., . . Blair, J. R. (2006). Choosing the lesser of two evils, the better of two goods: Specifying the roles of ventromedial prefrontal cortex and dorsal anterior cingulate in object choice.
Journal of Neuroscience, 26, 11379-11386. doi:10.1523/ JNEUROSCI.1640-06.2006

Blascovich, J., \& Mendes, W. B. (2000). Challenge and threat appraisals: The role of affective cues. In J. Forgas (Ed.), Feeling and thinking: The role of affect in social cognition (pp. 59-82). New York, NY: Cambridge University Press.

Bliese, P. (2009). Multilevel modeling in R (2.3): A brief introduction to $R$, the multilevel package and the nlme package. Retrieved from http:// cran.r-project.org/doc/contrib/Bliese_Multilevel.pdf

Botvinick, M. M. (2007). Conflict monitoring and decision making: Reconciling two perspectives on anterior cingulate function. Cognitive, Affective, and Behavioral Neuroscience, 7, 356-366. doi:10.3758/CABN.7.4.356

Botvinick, M. M., Braver, T. S., Barch, D. M., Carter, C. S., \& Cohen, J. D. (2001). Conflict monitoring and cognitive control. Psychological Review, 108, 624-652. doi:10.1037/0033-295X.108.3.624

Brown, K. W., Ryan, R. M., \& Creswell, D. J. (2007). Mindfulness: Theoretical foundations and evidence for its salutary effects. Psychological Inquiry, 18, 211-237. doi:10.1080/ 10478400701598298

Carver, C. S., \& Scheier, M. (1998). On the self-regulation of behavior. New York, NY: Cambridge University Press.

Chirkov, V. I., Ryan, R. M., \& Sheldon, K. M. (Eds.). (2011). Human autonomy in cross-cultural context: Perspectives on the psychology of agency, freedom, and well-being. Dordrecht, The Netherlands: Springer.

Deci, E. L., Koestner, R., \& Ryan, R. M. (1999). A meta-analytic review of experiments examining the effects of extrinsic rewards on intrinsic motivation. Psychological Bulletin, 125, 627-668. doi:10.1037/ 0033-2909.125.6.627

Deci, E. L., \& Ryan, R. M. (1985). Intrinsic motivation and selfdetermination in human behavior. New York, NY: Plenum Press.

Deci, E. L., \& Ryan, R. M. (1991). A motivational approach to self: Integration in personality. In R. Dienstbier (Ed.), Nebraska Symposium on Motivation: Vol. 38. Perspectives on motivation (pp. 237-288). Lincoln: University of Nebraska Press.

Deci, E. L., \& Ryan, R. M. (2000). The "what" and "why" of goal pursuits: Human needs and the self-determination of behavior. Psychological Inquiry, 11, 227-268. doi:10.1207/ S15327965PLI1104_01

Deci, E. L., \& Ryan, R. M. (2008). Facilitating optimal motivation and psychological well-being across life's domains. Canadian Psychology, 49, 14-23. doi:10.1037/0708-5591.49.1.14

Deci, E. L., Ryan, R. M., Gagné, M., Leone, D. R., Usunov, J., \& Kornazheva, B. P. (2001). Need satisfaction, motivation, and wellbeing in the work organizations of a former Eastern Bloc country. Personality and Social Psychology Bulletin, 27, 930-942. doi:10. 1177/0146167201278002

Delorme, A., \& Makeig, S. (2004). EEGLAB: An open source toolbox for analysis of single-trial EEG dynamics including independent component analysis. Journal of Neuroscience Methods, 134, 9-21. doi:10.1016/j.jneumeth.2003.10.009

Dhar, R., \& Nowlis, S. M. (1999). The effect of time pressure on consumer choice deferral. Journal of Consumer Research, 25, 369-384. doi:10.1086/209545

Di Domenico, S. I., Fournier, M. A., Ayaz, H., \& Ruocco, A. C. (2013). In search of integrative processes: Basic psychological need satisfaction predicts medial prefrontal activation during decisional conflict. Journal of Experimental Psychology: General, 142, 967-978. doi: 10.1037/a0030257

Di Domenico, S. I., Rodrigo, A. H., Ayaz, H., Fournier, M. A., \& Ruocco, A. C. (2015). Decision-making conflict and the neural efficiency hypothesis of intelligence: A functional near-infrared spectroscopy investigation. NeuroImage, 109, 307-317. doi:10.1016/j. neuroimage.2015.01.039 
Diederich, A. (2003). Decision making under conflict: Decision time as a measure of conflict strength. Psychonomic Bulletin and Review, 10, 167-176. doi:10.3758/BF03196481

Dollard, J., \& Miller, N. E. (1950). Personality and psychotherapy: An analysis in terms of learning, thinking, and culture. New York, NY: McGraw-Hill.

Duval, S., \& Wicklund, R. A. (1972). A theory of objective selfawareness. New York, NY: Academic Press.

Erikson, E. H. (1950). Childhood and society. New York, NY: Norton.

Erikson, E. H. (1968). Identity: Youth and crisis. New York, NY: Norton.

Evans, R. I. (1973). Jean Piaget: The man and his ideas. New York, NY: E. P. Dutton and Company.

Freud, S. (1969). An outline of psycho-analysis. New York, NY: Norton (Original work published 1940).

Gagné, M. (2003). The role of autonomy support and autonomy orientation in prosocial behavior engagement. Motivation and Emotion, 27, 199-223. doi:10.1023/A:1025007614869

Hirsh, J. B., Mar, R. A., \& Peterson, J. B. (2012). Psychological entropy: A framework for understanding uncertainty-related anxiety. Psychological Review, 119, 304-320. doi:10.1037/ a0026767

Ilardi, B. C., Leone, D., Kasser, T., \& Ryan, R. M. (1993). Employee and supervisor ratings of motivation: Main effects and discrepancies associated with job satisfaction and adjustment in a factory setting. Journal of Applied Social Psychology, 23, 1789-1805. doi:10.1111/ j.1559-1816.1993.tb01066.x

Jung, C. G. (1978). Aion: Researches into the phenomenology of the self. Princeton, NJ: Princeton University Press (Original work published 1951).

Kamano, D. K. (1963). Relationship of ego disjunction and manifest anxiety to conflict resolution. Journal of Abnormal and Social Psychology, 66, 281-284. doi:10.1037/h0046381

Kasser, T., \& Ryan, R. M. (1993). A dark side of the American dream: Correlates of financial success as a central life aspiration. Journal of Personality and Social Psychology, 65, 10-422. doi:10.1037/00223514.65.2.410

Kasser, T., \& Ryan, R. M. (1996). Further examining the American dream: Differential correlates of intrinsic and extrinsic goals. Personality and Social Psychology Bulletin, 22, 280-287. doi:10. 1177/0146167296223006

Lewin, K. (1935). A dynamic theory of personality. New York, NY: McGraw-Hill.

Luck, S. J. (2005). An introduction to the event-related potential technique. Cambridge, MA: MIT Press.

Luck, S. J., \& Gaspelin, N. (2016). How to get statistically significant effects in any ERP experiment (and why you shouldn't). Psychophysiology, (in press).

Markland, D., Ryan, R. M., Tobin, V. J., \& Rollnick, S. (2005). Motivational interviewing and self-determination theory. Journal of Social and Clinical Psychology, 24, 811-831. doi:10.1521/jscp. 2005.24.6.811

McAdams, D. P. (2013). The psychological self as actor, agent, and author. Perspectives on Psychological Science, 8, 272-295. doi:10. 1177/1745691612464657

Mendes, W. B. (2016). Emotion and the autonomic nervous system. In L. E. Barrett, M. Lewis, \& J. Haviland-Jones (Eds.), Handbook of emotions (4th ed.). New York, NY: Guilford Press.

Miller, N. E. (1944). Experimental studies of conflict. In J. McVicker Hunt (Ed.), Personality and the behavior disorders (Vol. 1, pp. 431-465). New York, NY: Ronald Press.

Miller, N. E. (1959). Liberalization of basic S-R concepts: Extensions to conflict behavior, motivation, and social learning. In S. Koch (Ed.), Psychology: Vol. 2. A study of a science (pp. 196-292). New York, NY: McGraw-Hill.

Miller, W. R., \& Rollnick, S. (2002). Motivational interviewing: Preparing people for change (2nd ed.). New York, NY: Guilford Press.
Miller, W. R., \& Rollnick, S. (2012). Meeting in the middle: Motivational interviewing and self-determination theory. International Journal of Behavioral Nutrition and Physical Activity, 9, 25. doi:10.1186/ 1479-5868-9-25

Minor, J., Miller, L., \& Ditrichs, R. (1968). The effect of an undecided alternative on resolution of approach-approach and avoidanceavoidance conflict situations. Psychonomic Science, 12, 275. doi: 10.3758/BF03331359

Murray, E. J. (1975). Resolution of complex decisional conflicts as a function of degree of avoidance. Journal of Research in Personality, 9, 177-190. doi:10.1016/0092-6566(75)90014-8

Nakao, T., Bai, Y., Nashiwa, H., \& Northoff, G. (2013). Resting-state EEG power predicts conflict-related brain activity in internally guided but not externally guided decision-making. NeuroImage, 66, 921. doi:10.1016/j.neuroimage.2012.10.034

Nakao, T., Mitsumoto, M., Nashiwa, H., Takamura, M., Tokunaga, S., Miyatani, M., . . . Watanabe, Y. (2010). Self-knowledge reduces conflict by biasing one of plural possible answers. Personality and Social Psychology Bulletin, 36, 455-469. doi:10.1177/0146167210363403

Nakao, T., Ohira, H., \& Northoff, G. (2012). Distinction between externally vs. internally guided decision-making: Operational differences, metaanalytical comparisons and their theoretical implications. Frontiers in Neuroscience, 6, 31. doi:10.3389/fnins.2012.00031

Nakao, T., Osumi, T., Ohira, H., Kasuya, Y., Shinoda, J., Yamada, J., \& Northoff, G. (2010). Medial prefrontal cortex-dorsal anterior cingulate cortex connectivity during behavior selection without an objective correct answer. Neuroscience Letters, 482, 220-224. doi:10. 1016/j.neulet.2010.07.041

Nakao, T., Osumi, T., Ohira, H., Kasuya, Y., Shinoda, J., \& Yamada, J. (2009). Neural bases of behavior selection without an objective correct answer. Neuroscience Letters, 459, 30-34. doi:10.1016/j.neulet. 2009.04 .056

Nakao, T., Takezawa, T., Shiraishi, M., \& Miyatani, M. (2009). Activation of self-knowledge reduces conflict during occupational choice: An ERP study. International Journal of Neuroscience, 119, 1640-1654. doi:10.1080/00207450802336790

Olvet, D. M., \& Hajcak, G. (2009). The stability of error-related brain activity with increasing trials. Psychophysiology, 46, 957-961. doi: 10.1111/j.1469-8986.2009.00848.x

R Development Core Team. (2011). $R$ : A language and environment for statistical computing. Vienna, Austria: R Foundation for Statistical Computing. Available at http://www.R-project.org/

Rogers, C. R. (1961). On becoming a person: A therapist's view of psychotherapy. New York, NY: Mariner Books.

Ryan, R. M. (1995). Psychological needs and the facilitation of integrative processes. Journal of Personality, 63, 397-427. doi:10.1111/j. 1467-6494.1995.tb00501.x

Ryan, R. M., \& Connell, J. P. (1989). Perceived locus of causality and internalization: Examining reasons for acting in two domains. Journal of Personality and Social Psychology, 57, 749-761. doi: 10.1037/0022-3514.57.5.749

Ryan, R. M., \& Deci, E. L. (2008). A self-determination approach to psychotherapy. The motivational basis for effective change. Canadian Psychology, 49, 186-193. doi:10.1037/a0012753

Ryan, R. M., Kuhl, J., \& Deci, E. L. (1997). Nature and autonomy: Organizational view of social and neurobiological aspects of selfregulation in behavior and development. Development and Psychopathology, 9, 701-728. doi:10.1017/S0954579497001405

Schluchter, M. D., \& Elashoff, J. T. (1990). Small-sample adjustments to tests with unbalanced repeated measures assuming several covariance structures. Journal of Statistical Computing and Simulation, 37, 69-87. doi:10.1080/00949659008811295

Schwartz, B. (2000). Self-determination: The tyranny of freedom. American Psychologist, 55, 79-88. doi:10.1037/0003-066X.55.1.79 
Sheldon, K. M. (2014). Becoming oneself: The central role of selfconcordant goal selection. Personality and Social Psychology Review, 18, 349-365. doi:10.1177/1088868314538549

Shenhav, A., Botvinick, M. M., \& Cohen, J. D. (2013). The expected value of control: An integrative theory of anterior cingulate cortex function. Neuron, 79, 217-240. doi:10.1016/j.neuron.2013.07.007

Shrout, P. E., \& Fleiss, J. L. (1979). Intraclass correlations: Uses in assessing rater reliability. Psychological Bulletin, 86, 420-428. doi:10.1037/0033-2909.86.2.420

Shultz, T. R., Léveillé, E., \& Lepper, M. R. (1999). Free choice and cognitive dissonance revisited: Choosing "lesser evils" versus "greater goods.". Personality and Social Psychology Bulletin, 24, 40-48. doi:10.1177/0146167299025001004

Snijders, T. A. B., \& Bosker, R. J. (2012). Multilevel analysis: An introduction to basic and advanced multilevel modeling (2nd ed.). London, England: Sage.

Vansteenkiste, M., \& Ryan, R. M. (2013). On psychological growth and vulnerability: Basic psychological need satisfaction and need frustration as a unifying principle. Journal of Psychotherapy Integration, 23, 263-280. doi:10.1037/a0032359

Vansteenkiste, M., Williams, G. C., \& Resnicow, K. (2012). Toward systematic integration between self-determination theory and motivational interviewing as examples of top-down and bottom-up intervention development: Autonomy or volition as a fundamental theoretical principle. International Journal of Behavioral Nutrition and Physical Activity, 9, 23. doi:10. 1186/1479-5868-9-23

Weinstein, N., Deci, E. L., \& Ryan, R. M. (2011). Motivational determinants of integrating positive and negative past identities. Journal of Personality and Social Psychology, 100, 527-544. doi:10.1037/ a0022150

Weinstein, N., Przybylski, A. K., \& Ryan, R. M. (2013). The integrative process: New research and future directions. Current Directions in Psychological Science, 22, 69-74. doi:10.1177/ 0963721412468001

Weinstein, N., \& Ryan, R. M. (2010). When helping helps: Autonomous motivation for prosocial behavior and its influence on well-being for the helper and recipient. Journal of Personality and Social Psychology, 98, 222-244. doi:10.1037/a0016984

West, S. G., Aiken, L. S., \& Krull, J. L. (1996). Experimental personality designs: Analyzing categorical by continuous variable interactions. Journal of Personality, 64, 1-48. doi:10.1111/j.1467-6494.1996. tb00813.x 